Cooper, of New York, the father of the American iron trade, and the founder of the Cooper Institute, probably the largest free technical school in the world, the three days of the meeting were given up to the reading and discussion of papers in the thorough and workmanlike manner that has distinguished the Institute from its earliest meeting to the present time. Of prominent interest among these communications was undoubtedly that by Messrs. Thomas and Gilchrist on the Elimination of Phosphorus in the Bessemer converter, describing a series of experiments in continuation of others previously brought before the Institute, made at Blaeravon and Dowlais in South Wales and at Messrs. Bolckow and Vaughan's steel-works in Cleveland. The essential novelty in these experiments is the use of lime and oxide of iron as a flux in the Bessemer converter, lime being also used as a refracting lining in place of the ordinary siliceous sand or ganister. By this comparatively simple change it is found that the highly phosphuretted iron of Cleveland, containing I per cent. and upwards of phosphorus, may be so completely purged from that objectionable metalloid as to yield a steel, or rather, to use the proposed international nomenclature, an "ingot metal," which in this particular compares favourably with that blown from hematite pigiron, the amount of phosphorus ranging from .03 to 0.15 per cent. in various samples.

The presence of a large excess of earthy base, i.e., lime, in the slags, appears to be the essential condition of success, and the formation of such a fluid basic slag at an early stage of the operation is of equal importance, as it enables the oxidation of both carbon and phosphorus to go on simultaneously. The composition of these slags is utterly unlike those obtained in the Bessemer process, as ordinarily worked, which are essentially similar to manganese augite; while those of the new process contain from 33 to 37 per cent. of lime, and about as much silica; though not exactly representing any natural mineral, are nearer in constitution to the olivine group of silicates. That the phosphorus is removed as phosphate of calcium, probably diffused through a mass of. smolten silicates of calcium iron and manganese, there can be but little doubt, but the point, apart from its practical bearing, is of considerable scientific interest, and it seems not unlikely that microscopic investigation might throw some light upon it, unless, indeed, the slags should prove so opaque as to resist this particular method of inquiry. At any rate, one cannot but be struck with the analogous occurrence of apatite in basalts and other igneous rocks containing a low proportion of silica.

As regards the practical value of the process it would be premature to speak; many of the points raised in the discussion by way of objection, such as the increased volume of slag produced, a serious nuisance in the comparatively confined space of a Bessemer casting pit, the possibly small duration of the converter linings, \&c., being obviously only matters of detail. That a very considerable success has been achieved in these experiments there can be no doubt, and that the iron smelters of Cleveland as well as those of Luxemburg and Lorraine will be fully alive to the advantages which the new process promises them is equally certain. At the same time the hematite iron trade, though not so completely master of the field as formerly, will no doubt be fully able to hold its own, and there will probably be fourd to be ample room for both east and west coast as steel producers. Some among us may hope as a consequence to hear less o the so-called phosphorus steels produced by dosing phos phorised iron with manganese, now that the more rational method of taling the phosphorus out of the iron may be used, in preference to disguising it.

The paper by Mr. Snelus covers nearly the same ground as that of Messrs. Thomas and Gilchrist, as it describes a number of experiments made in Bessemer converters with a lime lining first at Dowlais and subsequently Workington in Cumberland some years since with substantially the same results. That these experiments were not further carried out is sufficiently explained by the fact of the author being at the head of an establishment producing one of the purest qualities of cast-iron in the country, and therefore his interests were not in the direction of making lower class metal available ; and any one who knows how the West Cumberland Works have progressed under Mr. Snelus' management will find sufficient excuse for his name not being more prominently identified with the new process. The fact of a West Coast man having been the first to demonstrate the feasibility of steel-making from Cleveland iron is a source of gratification to the local papers, and to those who have neither Cumberland nor Cleveland proclivities, it will be gratifying to know that two of the three authors of the paper in question, namely, Messrs. Gilchrist and Snelus, are graduates of the Royal School of Mines. As a contribution to the working out of the practical details of the process, Mr. Riley's paper deserves notice, although no very considerable principle is involved. The use of lime as a lining for Bessemer and other steelmelting furnaces is attended with some difficulty, as the consolidation of dry quicklime by ramming and subsequent heating is in many ways an unsatisfactory method, and its conversion to a plastic mass by means of water is not possible, owing to the chemical changes set up by hydration. These inconveniences Mr. Riley proposes to remedy by making the lime plastic with petroleum or other hydrocarbon oils, giving a mass which can be moulded by pressure and consolidated by burning in the same way as ordinary fire-bricks, the small quantity of oil being driven off at the temperature of firing. The material used is the magnesium limestone of Yorkshire, which gives bricks sufficiently hard to resist carriage and a certain amount of hard usage. Of the other papers read, that by Mr. Pattinson, of Newcastle-on-Tyne, describing a new method of determining manganese in iron and iron ores, is of considerable value as giving an exact method of indirect analysis which can be carried out in a short time as an alternative to the rather tedious direct methods of determination at present in use.

The remaining communications, more particularly those on the various uses of steel, as for example, in ship building by Mr. Barnaby, in bridge building by Mr. Maynard, and in general engineering work by Mr. Adamson, though of interest, are more so from the discussions produced than from any positive information contained. The close of the meeting was marked by the announcement of Dr. Siemens' munificent offer of $10,000 l$. towards the building fund of a new house for the Institute and the other societies representing applied science, to be erected in Westminster, a project which has been spoken of for some time, but which will no doubt with such a favourable beginning soon become a reality. It is to be hoped that in erecting a new scientific palace, whether on the Thames Embankment or elsewhere, the example of Burlington House will not be followed, where a large and costly pile of buildings has been erected without a single good-sized meeting-room in any one of the houses.

\section{THE METEOROLOGICAL CONGRESS AT} ROME

THE second International Congress of Meteorologists has just been held at Rome, on the invitation of the Italian Government. At the time of the first Congress at Vienna in 1873 , it had been wished that a second should take place in three years' time, but for various reasons the meeting was postponed until Easter, 1879. Delegates were present from all the countries of Europe except Turkey, and Gen. Myer of the United States crossed the Atlantic, but, unfortunately, to arrive too late. The actual foreign delegates present were:-(Aus- 
tria) Dr. Hann, Dr. Lorenz, Dr. Paugger, Dr. Müller, and Lieut. Weyprecht ; (Hungary) Dr. Schenzl ; (Bavaria) Dr. v. Bezold; (Belgium) Prof. Houzeau ; (Denmark) Capt. Hoffmeyer; (England) Prof. Smith and Mr. Scott ; (France) M. Hervé Mangon, Prof. Mascart, Lieut. Brault; (Germany) Dr. Neumayer, Dr. Bruhns, Dr. Auwers ; (Greece) Prof. Kokides; (Holland) Dr. Snellen; (Norway) Prof. Mohn; (Portugal) Capt. de Brito Capello; (Russia) Prof. Wild; (Spain) M. Aguilar, Capt. Pujazon; (Sweden) Prof. Rubenson; (Switzerland) Prof. Plantamour; Italy sent Prof. Blaserna, Prof. Palmieri, Padre Denza, Prof. Tacchini, M. Salvatori, Prof. Pittei, and Prof. Cantoni. Of foreign guests there were present Dr. Hellmann, Prof. Mendeleef, Prof. Weihrauch, and Prof. Zenger.

Prof. Buys Ballot, the president of the Committee which had made the preparations for the Congress, was unavoidably absent, owing to domestic affliction, and his place was taken by Prof. Cantoni, who was elected president of the Congress. MM. Plantamour ${ }^{1}$ and Wild were elected vice-presidents, with Capt. Hoffmeyer and Mr. Scott as secretaries.

The proceedings were opened on April 14 by M. Depretis, the Premier, in the absence of the Minister of Agriculture and Commerce, M. Majorana Calatabiano. A reply to his speech had been prepared by Prof. Buys Ballot, and was read by M. Mascart. Mr. Scott then read the Report of the Permanent Committee of the Vienna Congress, containing a list of the special treatises prepared for submission to the Congress at Rome. The existence of these treatises, several of which are of considerable value, forms the most important feature of the proceedings of the meeting of 1879 .

For the consideration of the several questions of the programme, five committees were appointed: 1 . Crganisation; 2. Publications ; 3 . Instruments and Observations ; 4. Telegraphy, Maritime Meteorology and Agricultural Meteorology; 5. Distant Stations and Mountain Observations. The Committees met frequently, and the Congress held five general meetings, concluding its business in eight days of very hard work.

The following will give a general idea of the resolutions adopted :-

The idea of an international institute met with very little favour, but instead thereof, an international meteorological committee consisting of nine members was elected. This body possesses no executire powers, but is charged with the duty of endeavouring to forward the prosecution of definite inquiries into various meteorological problems by friendly co-operation between the several institutes and individuals who may be disposed to undertake such inquiries, as, e.g., the construction of isobaric charts for the globe. The committee has also to see to the carrying out of the resolutions of the Congress, and to report on the degree to which those of the Vienna congress have been carried out. The members of the committee are chosen from different countries, and their names are as follows:-

Buys-Ballot (Holland), Cantoni (Italy), Capello (Portugal), Hann (Austria), Mascart (France), Mohn (Norway), Neumayer (Germany), Scott (England), Secretary, Wild (Russia), President. All communications are to be addressed to Mr. Scott. As regards the form of publications, the schedules proposed in 1874 by the permanent committee of the Vienna congress were adopted, and, ir fact, are already very generally in use. The Congress took no measures to enforce uniformity of hours of observation, the problem presenting too many difficulties. Each country was invited to prepare for its own principal stations corrections for diurnal range for the more important elements. The preparation of a catalogue of existing meteorological literature, including papers in

$1 \mathrm{M}$. Plantamour's name was inadvertently omitted from our note of NATURE, vol. xix. p. 590. periodicals, was recommended, such catalogues having already appeared at Brussels and in London (for the library of the Meteorological Society).

With reference to the subjects embraced under "instruments and observations," the most important resolutions were the following :-

The different institutes were recommended to effect a comparison of their respective standard instruments; the method of determining the fixed points of thermometers proposed by M. Pernet in his report on the subject was provisionally approved; the Congress idid not venture to prescribe a single mode of exposure for thermometers suitable to all climates; the subject of earth-temperature was strongly recommended for study. The Congress received a communication from a $M$. de Rossi, on what he calls "endogenous meteorology," i.e., the influence of atmospherical changes on earthquakes, and recommended him to prosecute his studies further.

The regulation of the Vienna congress in favour of very large rain gauges was rescinded, as well as that prescribing a height of $4 \frac{1}{2}$ feet above the ground for the instrument.

The international telegraphic code proposed in 1874 was recommended for general adoption. It was not found practicable to introduce into it a notice of "cirrus" cloud observations, but this latter subject was strongly recommended for study.

The subject of ocean meteorology was left to the special offices which are occupied therewith. With reference to the simultaneous observations made for the U.S. Signal Office, the Congress hoped they will be continued. As to the construction of daily synoptic weather charts for the Atlantic and Europe, a joint proposal by Dr. Neumayer and Capt. Hoffmeyer to continue and enlarge the scope of the charts published by the latter gentleman was approved. In regard of agricultural meteorology, it was decided to recommend that a private conference of persons interested in and possessing special knowledge of the subject should be held in the course of the next twelve months.

With reference to the establishment of stations is distant islands, as, e.g., in the Pacific Ocean, it was decided that none such could be organised by international co-operation, but that individual governments should be requested to found stations in such localities, and that all maritime nations should be requested to instruct the officers of any exploring expeditions they may respectively send out to visit any such outlying stations as occasion may offer.

As regards Continental stations in low latitudes, the Congress resolved to request the Brazilian Government to establish meteorological stations, and to request the Royal Society of London to endeavour to secure the continuation of the publication of Mr. J. Allan Broun's work at Trevandrum. Several resolutions were passed relating to the importance of observations taken in balloons and on mountain tops. The subject of the changes in the size of glaciers, as indicating changes of climate, was recommended to the notice of the Alpine Clubs.

The final resolution of the Congress had reference to the proposal of Count Wilczek and Lieut. Weyprecht to maintain for a year a series of observing stations round the North Pole. It was resolved that, if possible, an official conference of representatives from governments disposed to co-operate in the undertaking should be held at Hamburg in October next; $M$. Weyprecht explaining that he could not accept a later date for the conference as his own departure for Nova Zembla, his chosen post, would take place before next spring, and as the funds for his expedition were already contributed. The meetings terminated on April 22.

The Congress was entertained with the most splendid hospitality. His Majesty the King received the delegates at a banquet on April 21, on which occasion they were 
personally presented to the King and Queen, who conversed most graciously with each of them. On the 22nd the Minister of Agriculture entertained the Congress at a State dinner. On the 2oth the Syndic of Rome had given a reception in the Capitoline Museum, which was illuminated for the occasion. For their own part the foreign delegates invited their Italian hosts to a dinner at the Hotel de Russie on the Igth.

The proceedings were closed by a very graceful and munificent act of hospitality. The entire Congress, with the ladies who had accompanied some of the members, received free tickets for Naples and became the guests of the Italian Government for two days and a half. An expedition to Vesuvius, which was arranged for them, proved a complete success. The courtesy and forethought of the Italian officials extended to every detail which could contribute to the comfort of their visitors. The day was one of unclouded enjoyment; the weather was a perfect specimen of an Italian spring, and Vesuvius was tranquil enough to allow the more adventurous members of the party to explore every part of the crater, only deigning to eject a few stones as Parthian arrows at the descending meteorologists.

The Congress at Rome will remain in the memory of all who took part in it as one of the pleasantest and most successful opportunities of international scientific intercourse which has ever been organised.

\section{OUR ASTRONOMICAL COLUMN}

TEMPEL's COMET (1867 II).- - The following ephemeris of this comet is deduced from M. Gautier's elements, but with the perihelion passage corrected to May 6.9537 G.M.T. to accord with the approximate position observed by Dr. Tempel on April 24 :-

\begin{tabular}{|c|c|c|c|c|c|c|c|c|c|c|}
\hline & & & & $1+6$ & & ans & $d i$ & & & \\
\hline 1879. & & $\begin{array}{r}\text { Righ } \\
\text { Ascensi }\end{array}$ & & & & $\begin{array}{l}\text { clina- } \\
\text { ion. }\end{array}$ & & from Earth. & & $\begin{array}{l}\text { Log.distan } \\
\text { from Sun }\end{array}$ \\
\hline ay 15 & $\ldots \mathbf{I}$ & & & & -16 & 17.6 & $\ldots$ & 9.8959 & $\ldots$ & 0.2487 \\
\hline 17 & $\ldots-$ & -49 & 15 & $\ldots$ & I6 & $36 \cdot 6$ & & & & \\
\hline 19 & - & -48 & 20 & $\ldots$ & 16 & $55^{\circ} 9$ & $\cdots$ & $9^{\circ 8911}$ & $\cdots$ & 0.2492 \\
\hline $2 \mathrm{I}$ & - & -47 & 20 & $\cdots$ & 17 & 15 & & & & \\
\hline $\begin{array}{l}23 \\
25\end{array}$ & 7 & -46 & 16 & $\cdots$ & 17 & 35.8 & $\cdots$ & $9^{\circ} 8880$ & $\cdots$ & 0.2498 \\
\hline $\begin{array}{l}25 \\
27\end{array}$ & 7 & $\begin{array}{l}-45 \\
-43\end{array}$ & $\begin{array}{r}8 \\
5^{8}\end{array}$ & $\begin{array}{l}\cdots \\
\ldots\end{array}$ & & $\begin{array}{l}56.3 \\
17.5\end{array}$ &. & 9.8866 & $\ldots$ & 0.2506 \\
\hline 29 & - & -42 & 45 & . & 18 & $38 \cdot I$ & & & & \\
\hline $3 I$ & $\ldots-$ & $-4 I$ & $3 \mathbf{I}$ & $\cdots$ & 18 & 59.3 & $\cdots$ & $9^{.8871}$ & $\cdots$ & 0.2515 \\
\hline ne 2 & & -40 & I6 & $\ldots$ & 19 & $20 \cdot 6$ & & & & \\
\hline 4 & - & -39 & 2 & $\cdots$ & 19 & $42^{\circ} \mathrm{O}$ & $\cdots$ & 9.8895 & $\cdots$ & 0.2527 \\
\hline & & 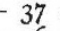 & & & 20 & 3.4 & & & & \\
\hline 8 & 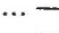 & $\begin{array}{r}36 \\
-35\end{array}$ & 38 & & 20 & 24.8 & $\cdots$ & 9.8937 & $\cdots$ & 0.2539 \\
\hline 12 & & 63 & 23 & $\ldots$ & 21 & $7 \cdot 2$ &.. & $9 \cdot 8996$ & & 0.2554 \\
\hline
\end{tabular}

The intensity of light is at a maximum about May 26, but is not then very materially greater than on April 24, when the comet was described by Dr. Tempel as a faint object. In 1867 it was observed at Athens until the theoretical intensity of light had diminished to $0.2 \mathrm{I}$, so that with the larger telescopes in the southern hemisphere observations may be possible in August. The position for August 13.5 is in R.A. 16h. $58.8 \mathrm{~m}$., Decl. $-29^{\circ} 11^{\prime}$. When brightest in 1867 , the nucleus was star-like and of $97 \mathrm{~m}$., the value of $\mathrm{I}$. at the time being $\mathrm{I} \cdot 23$.

During the ensuing revolution considerable perturbation may again result from the action of the planet Jupiter, though not to so great an extent as in the revolution 1867-73. Using the above time for perihelion passage in the present year and taking the mean daily motion, $593^{\prime \prime} \cdot 184$, it appears that the least distance of the comet from the planet will be about 0.58 of the earth's mean distance from the sun, in the middle of October $188 \mathrm{I}$, and that from the beginning of July, I88r, to the middle of January, 1882 , the comet will always be within 0.65 ; this will again necessitate a rigorous calculation of the perturbations to insure a near prediction of the comet's track in the heavens in 1885 .

It was at one time suggested that the object detected by M. Goldschmidt on May 16, 1855, while searching for De Vico's comet of short period, might have been the comet of which we are writing; but the late Dr. von Asten undertook the calculation of the perturbations backward for two revolutions from 1867 , and found that the comet being in peribelion on February $\mathrm{I}, 1856$, with elements not very different from those of 1867 , could not have been identical with Goldschmidt's nebulosity. So far, therefore, as is known at present, there is no recorded observation of Tempel's comet previous to April 3, I867, notwithstanding it may have performed many earlier revolutions in the restricted orbit it now describes; but the case is similar with other comets of short period.

Brorsen's COMET.-Dr. Krueger has kindly sent us two meridian observations, made at Helsingfors, of the star over which Major Tupman witnessed a nearly central transit of this comet on May 3 (NATURE, vol. xx. p. 27). The star was rated 8.7 mag., and its mean position for I $875^{\circ} \mathrm{O}$ was R.A. 6h. 9m. I4.845., Decl. $+6 \mathrm{I}^{\circ} 28^{\prime} 8^{\prime \prime} \cdot 5$. Whence the apparent position of the comet by Major Tupman's observation was on May 3, at Ioh. IIm. I4s. G.M.T. in R.A., 6h. 9m. $39^{\circ} 15^{5}$., Decl. +61 $28^{\prime} 30^{\prime \prime} \cdot 9$, showing corrections to the ephemeris, published in this column, of +13 s. in R.A., and $+2^{\prime}$ in declination.

ANNUAIRE POUR L'AN I879, PUBlié PAR LE BUREAU DES LONGITUDES. - It has not been from want of appreciation of the astronomical contents of this small volume, so ably edited by M. Lœwy, that earlier allusion to it has not been found in this column. It provides information of a kind which is not to be met with in so collective a form elsewhere, and must be a valuable adjunct to the astronomical amateur, who needs reference to 'a really reliable authority on such details as the maxima and minima of variable stars and the general elements of the solar system, including periodical comets. M. Lœwy presents in one list the positions and limiting magnitudes of the variable stars of which the periods are known, and in a second list similar particulars of a large number of stars known to be variable, but of which the periods have not yet been determined; these lists are followed by an ephemeris of maxima and minima, arranged in order of date, with the minima of the more rapid variables, Algol, $\lambda$ Tauri, S Cancri, $\delta$ Libræ, and U Coronæ. There is also a carefully-prepared list of the elements of the minor planets to No. I9I inclusive, such a catalogue, in fact, as has often been inquired for by those who do not see the Berliner Astronomisches Jahrbuch. The general contents of the Annuaire are as full and varied as usual, but for the reasons named it has now an especial value for amateurs of astronomy, and its almost nominal price places it within reach of all. M. Janssen makes an important addition in his "Notice sur les Progrès récent de la Physique solaire," which is accompanied by a photograph of a portion of the sun's disc, taken at the observatory at Meudon, June I, 1878 , illustrating the rapid transformations occurring in the photospheric network and granulations within less than an hour.

\section{AN INTER-OCEANIC CANAL}

T $\mathrm{O}-\mathrm{DAY}$ the long-talked-of International Congress on the subject of a canal across the Central American Isthmus meets in Paris under the presidency of $M$. De Lesseps. This question is a very old one, but the morement which has led up to the present Congress commenced only in 1875 , at the instigation of Lieut. Lucien N. B. Wyse, of the French Navy. At the International Congress of Geography of that year the subject of the 